\title{
Pharmacogenetic analysis of human steroid $5 \alpha$ reductase type II: comparison of finasteride and dutasteride
}

\author{
Nick Makridakis ${ }^{1}$ and Juergen K V Reichardt ${ }^{1,2}$ \\ ${ }^{1}$ Department of Biochemistry and Molecular Biology and Institute for Genetic Medicine, Keck School of Medicine of the University of Southern California, 2250 Alcazar Street, \\ IGM240, Los Angeles, California 90089-9075, USA \\ ${ }^{2}$ Department of Preventive Medicine, Keck School of Medicine of the University of Southern California, 2250 Alcazar Street, IGM240, Los Angeles, California 90089-9075, USA
}

(Requests for offprints should be addressed to J K V Reichardt, 2250 Alcazar Street, IGM240, Los Angeles, CA 90089-9075, USA; Email: reichard@ usc.edu)

(J K V Reichardt is currently at University of Sydney, Medical Foundation Building (K25), 92-94 Parramatta Rd, Camperdown, New South Wales 2042, Australia)

\begin{abstract}
Human steroid $5 \alpha$-reductase type II is a prostate-specific, membrane-associated enzyme that catalyzes the conversion of testosterone to dihydrotestosterone, the most potent androgen in the prostate gland. Genetic variants of this enzyme have been associated with both the development and the progression of prostate cancer. Both finasteride and dutasteride are competitive inhibitors of the type II steroid $5 \alpha$-reductase that have been effectively used for the treatment of benign prostatic hyperplasia. Finasteride has also been successfully utilized for prostate cancer chemoprevention. We here investigate $5 \alpha$-reductase inhibition assays in vitro to measure the effect of incubation time on the apparent inhibition constant $\left(K_{\mathrm{i}}\right)$ for both constitutional and somatic (prostate cancer) enzyme variants. Our systematic pharmacogenetic analysis shows that both finasteride and dutasteride are slow, time-dependent inhibitors of steroid $5 \alpha$-reductase type II, and that the inhibition kinetics depend on the $5 \alpha$-reductase genotype. We also show that, overall, dutasteride is a more efficient steroid $5 \alpha$-reductase inhibitor than finasteride. Based on our data, we are able to map areas of the enzyme that are responsible for this time-dependent inhibition for either (or both) enzyme inhibitor(s). This comprehensive pharmacogenetic analysis of steroid $5 \alpha$-reductase variants unveiled significant pharmacogenetic variation for both finasteride and dutasteride and thus should be taken into account when designing protocols for treatment and/or chemoprevention of prostatic diseases with either one of these $5 \alpha$-reductase inhibitors since there is considerable pharmacogenetic variation for both drugs.
\end{abstract}

Journal of Molecular Endocrinology (2005) 34, 617-623

\section{Introduction}

The prostate gland depends on androgens for both its growth and development (Cheng et al. 1993). We have reported evidence that increased intraprostatic androgen metabolism, particularly through genetic variants of the enzyme steroid $5 \alpha$-reductase, may play an important role in both predisposition to prostate cancer (Makridakis et al. 1999) as well as prostate cancer progression (Makridakis et al. 2004). Human prostatic (type II) steroid $5 \alpha$-reductase is encoded by the SRD5A2 gene located in chromosome band 2p23 (Russell \& Wilson 1994). Steroid $5 \alpha$-reductase is a membraneassociated enzyme that catalyzes the conversion of testosterone to dihydrotestosterone (DHT), the most potent androgen in the prostate (e.g. Cheng et al. 1993). Thus, genetic variants encoded by the SRD5A2 gene may play an important role in both the development and the progression of prostate cancer (Ross et al. 1998).

Finasteride is a specific competitive inhibitor of the prostatic (type II) steroid $5 \alpha$-reductase, both in vivo and in vitro (Stoner 1996, Span et al. 1999). These properties have made finasteride an attractive drug for the treatment of benign prostatic hyperplasia $(\mathrm{BPH})$ (McConnell et al. 1998, Lowe et al. 2003) and prostate cancer chemoprevention (Thompson et al. 2003), with successful results. Specifically, the prostate cancer prevention trial (PCPT) showed that treatment of men 55 years of age or older with finasteride resulted in a significant decrease in prostate cancer incidence measured over a seven-year period (Thompson et al. 2003), suggesting that finasteride prevents or delays the appearance of prostate cancer. However, finasteride treatment also resulted in a significant increase in the incidence of prostate tumors of high grade (7 or higher) Gleason score (Thompson et al. 2003). Dutasteride (or GG745), a competitive inhibitor of both steroid $5 \alpha$-reductase isozymes (type I and type II; Bramson et al. 1997), has also been shown to improve the symptoms associated with $\mathrm{BPH}$ without any significant increase in adverse side effects (Brown \& Nuttall 2003, Clark et al. 2004).

We have reported significant genetic and pharmacogenetic variation for both finasteride and dutasteride at 
the SRD5A2 locus in both somatic prostate cancer tissue and constitutional DNA of prostate cancer patients (Makridakis et al. 2000, 2004). Some of these SRD5A2 mutations resulted in increased enzyme activity and lowered inhibition by finasteride (Makridakis et al. 2000, 2004). These findings suggest that the presence of specific SRD5A2 mutants that are not efficiently inhibited by finasteride may, at least partially, explain the unexpected finding of an increase in high grade prostate cancer rate in the PCPT (reported by Thompson et al. 2003) since these mutants might result in more aggressive growth of tumors.

The kinetics of steroid $5 \alpha$-reductase inhibition that we reported previously (Makridakis et al. 2000, 2004) were based on 10-min incubations for all enzyme variants. Finasteride, however, dissociates from the enzyme very slowly, and therefore is a time-dependent inhibitor of steroid $5 \alpha$-reductase (Faller et al. 1993, Tian et al. 1994, 1995). In addition, dutasteride (Frye et al. 1998), like finasteride, retains the $\Delta^{1,2}$ bond that is critical for time-dependent inhibition in 4-azasteroids (Russell \& Wilson 1994). Thus we decided to compare the kinetics of steroid $5 \alpha$-reductase inhibition using 10- and 30-min incubation of the enzyme with either finasteride or dutasteride.

We report here that, like finasteride, dutasteride is a time-dependent inhibitor of steroid $5 \alpha$-reductase type II. We also show that dutasteride is a more efficient steroid $5 \alpha$-reductase inhibitor than finasteride for most of the enzyme variants that we studied. Based on our data, we are able to map areas of the enzyme that when mutated result in time-independent inhibition for either (or both) enzyme inhibitor(s). This comprehensive pharmacogenetic analysis of steroid $5 \alpha$-reductase variants unveiled significant pharmacogenetic variation for both finasteride and dutasteride and this should be taken into account when designing protocols for treatment and/or chemoprevention of prostatic diseases with either one of these drugs.

\section{Materials and methods}

\section{Steroid inhibitors}

Finasteride was obtained from Merck (Rahway, NJ, USA) and dutasteride was synthesized by Pharmacia \& Upjohn (Nerviano, Italy) (Makridakis et al. 2000).

\section{Pharmacogenetic analysis}

Individual missense substitutions were reconstructed in the SRD5A2 cDNA mammalian expression vector pS303-5 $\alpha$ R2 (originally obtained from Dr D Russell, UT Southwestern Medical College, Dallas, TX, USA), by site-directed mutagenesis using the QuickChange kit (Stratagene, San Diego, CA, USA) with custom primers
(Invitrogen, Carlsbad, CA, USA) (Makridakis et al. 2000). The various SRD5A2 cDNAs were electroporated into COS 7 cells together with a $\beta$-galactosidase control plasmid (pCMV $\beta$, obtained originally from Dr Larry Kedes, University of Southern California, Los Angeles, CA, USA), and the respective protein extracts were collected $48 \mathrm{~h}$ later, by sonication. Total protein was quantified with a BioRad protein assay (Hercules, CA, USA) and $\beta$-galactosidase assay was then performed to normalize the extracts for differences in transfection efficiency (Makridakis et al. 2000). Normalized extract amounts were then used for $5 \alpha$-reductase activity assay, as described (Makridakis et al. 2000). Briefly, a mixture containing $5 \mathrm{mM}$ NADPH (Sigma, St Louis, MO, USA) and normalized protein extracts was added to specific amounts of each inhibitor at room temperature. Then, 0.8 or $1.6 \mu \mathrm{M}\left[{ }^{14} \mathrm{C}\right]$ testosterone (NEN, Boston, MA, USA) and $0 \cdot 1 \mathrm{M}$ Tris-citrate buffer of optimum $\mathrm{pH}$ for each variant (Makridakis et al. 2000, 2004) were added to the mix, and the reactions were placed at $37^{\circ} \mathrm{C}$ for either 10 or $30 \mathrm{~min}$. Initially, the concentration of the inhibitor was varied in 10-fold increments between $10^{-10}$ and $10^{-5} \mathrm{M}$, to approximate the apparent inhibition constant $\left(K_{\mathrm{i}}\right)$. After the initial approximation, the concentration was varied in five increments around the approximate $K_{\mathrm{i}}$ in triplicate experiments. Following incubation at $37^{\circ} \mathrm{C}$, the reactions were stopped with methylene chloride, and after extraction of the organic phase, steroids were dried, redissolved in ethanol and separated by thin-layer chromatography (TLC) using K6 silica TLC plates (Whatman, Clifton, NJ, USA) (Makridakis et al. 1999, 2000). Dried TLC plates were then exposed on phosphorimager screens (Molecular Dynamics, Mountain View, CA, USA) and quantified on a Storm phosphorimager (Molecular Dynamics). Then, substrate-to-product conversion values were translated into velocity values and plotted using Cricket Graph 1.3 (Cricket Software, Malvern, PA, USA). Linear regression analysis of the respective LineweaverBurk plots was used to calculate $K_{\mathrm{i}}$ values. The apparent $K_{\mathrm{i}}$ for each variant was determined by averaging the $K_{\mathrm{i}}$ values from three independent experiments. Further experimental details can be found in Makridakis et al. (2000).

\section{Results}

We previously reported significant genetic and pharmacogenetic variation at the SRD5A2 locus for both finasteride and dutasteride in both somatic prostate cancer tissue and constitutional DNA of prostate cancer patients (Makridakis et al. 2000, 2004). Some of the SRD5A2 mutations we characterized are common and/or recurrent, including the A49T (alanine-49 to threonine) mutation, which has been found to be 
Table 1 Apparent inhibition constant $\left(K_{\mathrm{i}}\right)$ values for finasteride (the wild-type protein and enzyme variants) at the standard reaction time of 10 mins and at the extended reaction time of 30 mins

\begin{tabular}{|c|c|c|c|}
\hline & \multicolumn{2}{|c|}{ Reaction time } & \multirow{2}{*}{$\begin{array}{l}\text { Change } \\
\text { (10 min vs } 30 \mathrm{~min})\end{array}$} \\
\hline & $10 \min$ & $30 \mathrm{~min}$ & \\
\hline Wild type (normal variation) & $60(52-72)$ & $23(17-29)$ & $2 \cdot 6$ \\
\hline \multicolumn{4}{|l|}{ Constitutional variants } \\
\hline C5R & 63 & 22 & 2.9 \\
\hline P30L & 420 & 120 & 3.5 \\
\hline $\mathrm{P} 48 \mathrm{R}$ & 22 & 8 & $2 \cdot 8$ \\
\hline A49T & 180 & 270 & 0.7 \\
\hline A51T & 49 & 8 & $6 \cdot 1$ \\
\hline V89L & 113 & 64 & $1 \cdot 8$ \\
\hline T187M & 70 & 19 & 3.7 \\
\hline F194L & 7 & 1.9 & 3.7 \\
\hline $\mathrm{R} 227 \mathrm{Q}$ & 260 & 55 & $4 \cdot 7$ \\
\hline F234L & 200 & 38 & $5 \cdot 3$ \\
\hline Range & 60 & 142 & \\
\hline \multicolumn{4}{|l|}{ Somatic variants } \\
\hline V3I & 27 & 11 & 2.5 \\
\hline A49T & 180 & 270 & 0.7 \\
\hline V63M & 38 & 6 & $89 \cdot 7$ \\
\hline F118L & 5 & 3.2 & 1.6 \\
\hline G183D & 45 & 15 & 3 \\
\hline V189A & 90 & 35 & $2 \cdot 6$ \\
\hline G191E & 40 & 13 & 3.1 \\
\hline L221P & 57 & 22 & 2.6 \\
\hline L226P & 105 & $5 \cdot 3$ & $19 \cdot 8$ \\
\hline A248V & 85 & $2 \cdot 6$ & $32 \cdot 7$ \\
\hline Range & 36 & 104 & \\
\hline
\end{tabular}

Range $=$ fold variation between the lowest and highest values.

involved in prostate cancer predisposition and progression (Makridakis et al. 1999, 2004). The apparent $K_{\mathrm{i}}$ for both finasteride and dutasteride in those experiments was calculated after transient expression of the reconstructed variant clones in mammalian cells followed by 10-min in vitro enzyme assays (Makridakis et al. 2000, 2004). However, finasteride is a slow, time-dependent inhibitor of steroid $5 \alpha$-reductase (Faller et al. 1993, Tian et al. 1994, 1995). Therefore, longer finasteride incubations with the wild-type enzyme are expected to result in better inhibition, or lower apparent $K_{\mathrm{i}}$ (see e.g. Moss et al. 1996). We decided to test this hypothesis for both finasteride and dutasteride and all the steroid $5 \alpha$-reductase type II variants, using 30-min incubations.

As expected, the apparent $K_{\mathrm{i}}$ for finasteride dropped significantly, from $60 \mathrm{nM}$ for the10-min enzyme assays to $23 \mathrm{nM}$ for the 30 -min enzyme assays for the normal (aka wild-type) protein (Table 1). The apparent $K_{\mathrm{i}}$ for dutasteride also dropped significantly, from $17 \mathrm{nM}$ to $4 \cdot 3 \mathrm{nM}$ (Table 2), suggesting that, like finasteride, the 4-azasteroid dutasteride is also a slow, time-dependent inhibitor of steroid $5 \alpha$-reductase type II. The majority of the steroid $5 \alpha$-reductase enzyme variants resulted in a reduction of the apparent $K_{\mathrm{i}}$ for both inhibitors from the 10-min to the 30-min reaction, and thus behave like the wild-type enzyme (Tables 1 and 2). The significance of these findings is emphasized by the small variability observed in the values measured from three independent experiments (Tables 1 and 2 and data not shown). However, several variants resulted in an increase of the apparent $K_{\mathrm{i}}$ for each inhibitor or no significant change between the 10- and 30-min reactions (Fig. 1 and Tables 1 and 2), and thus they exhibit time-independent inhibition. The steroid $5 \alpha$-reductase variants that resulted in time-independent inhibition affect enzyme residues in both the amino-terminus and the carboxyterminus of the protein (residues 49, 118, 226, 227 and 234; Fig. 1), and include the A49T, a gain-of-function mutation in the enzyme (Makridakis et al. 1999) that has been associated with both predisposition and progression of prostate cancer (Makridakis et al. 1999, Jaffe et al. 2000, Makridakis et al. 2004).

Comparison of the apparent $K_{\mathrm{i}}$ values for each inhibitor suggests that dutasteride may be a more efficient steroid $5 \alpha$-reductase inhibitor (due to its lower 
Table 2 Apparent inhibition constant $\left(K_{\mathrm{i}}\right)$ values for dutasteride (the wild-type protein and enzyme variants) at the standard reaction time of 10 mins and at the extended reaction time of 30 mins

\begin{tabular}{|c|c|c|c|}
\hline & \multicolumn{2}{|c|}{ Reaction time } & \multirow{2}{*}{$\begin{array}{l}\text { Change } \\
(10 \text { min vs } 30 \mathrm{~min})\end{array}$} \\
\hline & $10 \min$ & $30 \mathrm{~min}$ & \\
\hline Wild type (normal variation) & $17(15-20)$ & $4.3(3.9-4.9)$ & $4 \cdot 0$ \\
\hline \multicolumn{4}{|l|}{ Constitutional variants } \\
\hline C5R & 18 & 4.5 & $4 \cdot 0$ \\
\hline P30L & 12 & 6 & $2 \cdot 0$ \\
\hline P48R & 27 & $3 \cdot 8$ & $7 \cdot 1$ \\
\hline A49T & $1 \cdot 1$ & $2 \cdot 3$ & 0.5 \\
\hline A51T & 29 & $2 \cdot 2$ & $13 \cdot 2$ \\
\hline V89L & 9 & $2 \cdot 1$ & $4 \cdot 3$ \\
\hline T187M & 21 & 5 & $4 \cdot 2$ \\
\hline F194L & 21 & 12 & $1 \cdot 8$ \\
\hline $\mathrm{R} 227 \mathrm{Q}$ & $3 \cdot 2$ & 7 & 0.5 \\
\hline F234L & 6 & 11 & 0.5 \\
\hline Range & 25 & 6 & \\
\hline \multicolumn{4}{|l|}{ Somatic variants } \\
\hline V3I & 93 & 15 & $6 \cdot 2$ \\
\hline A49T & $1 \cdot 1$ & $2 \cdot 3$ & 0.5 \\
\hline V63M & 36 & 5 & $7 \cdot 2$ \\
\hline F118L & 4 & 0.5 & 8 \\
\hline G183D & 13 & $3 \cdot 1$ & $4 \cdot 2$ \\
\hline V189A & 23 & 5 & 4.6 \\
\hline G191E & 25 & 5 & 5 \\
\hline L221P & 14 & $4 \cdot 2$ & $3 \cdot 3$ \\
\hline L226P & 9 & 7 & 1.3 \\
\hline A248V & 13 & 2.9 & 4.5 \\
\hline Range & 85 & 30 & \\
\hline
\end{tabular}

Range $=$ fold variation between the lowest and highest values.

apparent $K_{\mathrm{i}}$ ) than finasteride for most of the enzyme variants, including the wild-type enzyme and the A49T mutant (Tables 1 and 2). The P30L and A49T mutants, in particular, display a more than 100-fold lower apparent $K_{\mathrm{i}}$ for dutasteride than for finasteride, independently of reaction time (Tables 1 and 2). However, two of the enzyme variants do not follow this trend: the F194L variant (independently of reaction time) and the P48R variant (but only in the 10-min reaction) display lower apparent $K_{\mathrm{i}}$ (higher affinity) for finasteride than dutasteride (Tables 1 and 2).

Overall, we report a significant pharmacogenetic variation for both somatic and constitutional SRD5A2 variants and for both finasteride and dutasteride (Tables 1 and 2). The distribution of the apparent $K_{\mathrm{i}}$ for finasteride for the distinct SRD5A2 missense substitutions

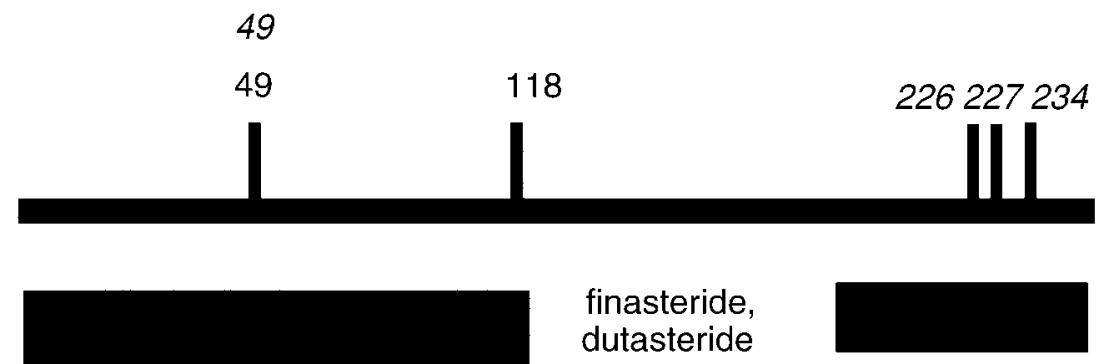

Figure 1 Mapping of enzyme residues that do not show time-dependent inhibition for finasteride (regular font) and dutasteride (italics). Black blocks under the sequence indicate $5 \alpha$-reductase enzyme binding regions for both finasteride and dutasteride (deduced from the effect of specific enzyme variants on the apparent $K_{\mathrm{i}}$ ). 
varied 84-fold (5-420 $\mathrm{nM}$ ) in the 10-min reactions and 142-fold (1.9-270 nM) in the 30-min reactions (Table 1). The distribution of the apparent $K_{\mathrm{i}}$ for dutasteride varied 85 -fold $(1 \cdot 1-93 \mathrm{nM})$ in the 10 -min reactions and 30-fold $(0 \cdot 5-15 \mathrm{nM})$ in the 30-min reactions (Table 2). Thus, 30-min incubations with dutasteride resulted in the lowest apparent $K_{\mathrm{i}}$ values overall and the lowest variation (Tables 1 and 2).

\section{Discussion}

Both finasteride and dutasteride are important 4 -azasteroid inhibitors of steroid $5 \alpha$-reductase that have been successfully utilized in vivo for the treatment and prevention of prostatic diseases. We previously reported significant pharmacogenetic variation of steroid $5 \alpha$ reductase for both finasteride and dutasteride in both somatic prostate cancer tissue and constitutional DNA (Makridakis et al. 2000, 2004). Those results, however, were based on 10-min reactions, while finasteride is a slow, time-dependent inhibitor of steroid $5 \alpha$-reductase (e.g. Faller et al. 1993, Tian et al. 1994). Thus, we reasoned that longer incubations with either inhibitor would be better approximations of the true inhibition in vivo. Due to the lability of the enzyme in vitro and the loss of linearity in the DHT production versus time curve after $40 \mathrm{~min}$ for the overactive A49T mutant (data not shown), we decided to use 30-min incubations for all the enzyme variants as the longer reaction time.

Comparison of the apparent $K_{\mathrm{i}}$ values between our standard $(10 \mathrm{~min})$ reactions and the extended $(30 \mathrm{~min})$ reactions for finasteride (Table 1) indicates that, as reported previously, finasteride is a time-dependent inhibitor of steroid $5 \alpha$-reductase. This fact is not only true for the wild-type protein, but also for most of the enzyme variants, whether constitutional or somatic (Table 1). Dutasteride is a dual (i.e. type I and type II) 5a-reductase inhibitor (Bramson et al. 1997) and thus may be more efficacious in reducing DHT levels in the blood, in vivo. In addition, most of the $5 \alpha$-reductase enzyme variants resulted in significantly lower apparent $K_{\mathrm{i}}$ values for dutasteride in the 30 -min reactions compared with the 10-min reactions (Table 2). Therefore, dutasteride is, like finasteride, a slow, time-dependent inhibitor of steroid $5 \alpha$-reductase. This finding is not surprising since both dutasteride and finasteride retain the $\Delta^{1,2}$ bond that is critical for time-dependent inhibition in 4-azasteroids (Russell \& Wilson 1994). These results also suggest a similar mechanism of time-dependent steroid $5 \alpha$-reductase inhibition for both finasteride and dutasteride.

Comparison of the apparent $K_{\mathrm{i}}$ values for each inhibitor suggests that dutasteride was the steroid $5 \alpha$-reductase inhibitor that exhibited the lowest appar- ent $K_{\mathrm{i}}$ for most steroid $5 \alpha$-reductase variants, including the wild-type, in both the 10-min and the 30-min reactions (Tables 1 and 2). The only exceptions to this observation were the F194 L variant (independently of reaction time) and the $\mathrm{P} 48 \mathrm{R}$ variant (but only in the 10 -min reaction). The disease-relevant A49T variant is of particular interest, since it is inhibited much more efficiently by dutasteride than finasteride, irrespective of the reaction time (Tables 1 and 2). Overall, the dual $5 \alpha$-reductase inhibitor, dutasteride, has higher affinity for steroid $5 \alpha$-reductase type II than finasteride, irrespective of genotype. Dutasteride is also expected to result in lower pharmacogenetic variation than finasteride in vivo, since it displays significantly lower pharmacogenetic variation of the apparent $K_{\mathrm{i}}$ than finasteride in the 30-min assays (see below; Tables 1 and 2). Thus, this compound may also be a better choice in vivo.

Thirty-minute $5 \alpha$-reductase inhibition reactions are expected to be more representative of the in vivo $5 \alpha$-reductase inhibition than the 10 -min reactions we previously reported (Makridakis et al. 2000, 2004). The distribution of the apparent $K_{\mathrm{i}}$ for the distinct SRD5A2 variants in the 30-min reactions varied 142-fold $(1.9-270 \mathrm{nM})$ for finasteride (Table 1) and 30-fold (0.5 nM-15 nM) for dutasteride (Table 2). Thus the apparent $K_{\mathrm{i}}$ values for the distinct SRD5A2 variants vary widely, irrespective of reaction time. This significant SRD5A2 pharmacogenetic variation may be important in vivo and should be taken into account when using finasteride or dutasteride for the treatment or prevention of prostate cancer. The PCPT trial reported that finasteride treatment in men followed over seven years resulted in a significant decrease in the overall rates of prostate cancer, but also in a significant increase in the rates of high-grade prostate tumors (Thompson et al. 2003). This unexpected finding of an increase in high grade prostate cancer rate in the PGPT may, at least partially, be explained by the presence of specific SRD5A2 variants (like A49T) in a subset of the study population that are not efficiently inhibited by finasteride. For individuals carrying the A49T allele, dutasteride might have been a better choice (Table 2 versus Table 1). Thus, future trials such as the PCPT and treatment protocols using $5 \alpha$-reductase inhibitors should consider genotyping men for SRD5A2 variants. In fact, we note that the pharmacogenetic inhibition increases for finasteride with time (Table 1) while it decreases for dutasteride (Table 2). This may suggest that dutasteride has a 'tighter' range for allelic and somatic variants, which may lessen the still considerable impact of pharmacogenetic variation in vitro. Thus, this compound may be generally better tolerated in vivo as well.

The inclusion of a high number of naturally occurring constitutional or somatic (prostate cancer) SRD5A2 variants in our pharmacogenetic analysis allowed us to identify areas of the protein that are important for the 
slow, time-dependent inhibition, for both 4-azasteroid inhibitors (Fig. 1). The wild-type as well as most of the steroid $5 \alpha$-reductase variants resulted in a reduction of the apparent $K_{\mathrm{i}}$ for both inhibitors from the 10-min to the 30-min reaction, and thus display time-dependent inhibition (Tables 1 and 2). However, several $5 \alpha$ reductase variants resulted in time-independent inhibition: (a) the A49T and F118 L variants for finasteride, and (b) the A49T, L226P, R227Q and F234 L variants for dutasteride (Fig. 1, Tables 1 and 2). These enzyme variants affect residues in both the amino-terminus and the carboxy-terminus of the protein (Fig. 1). Comparison of the wild-type versus mutant residue at positions 49, 118, 226, 227 and 234 indicates that the mutant residues are less hydrophobic. Indeed, the average hydropathy index (Kyte \& Doolittle 1982) for residues 49 and 118 (for finasteride) is $+2 \cdot 3$ for the wild-type residues and +1.5 for the mutant residues. Similarly, for dutasteride, the average hydropathy index (Kyte \& Doolittle 1982) for residues 49, 226, 227 and 234 is $+1 \cdot 0$ for the wildtype residues and $+0 \cdot 3$ for the mutant residues. Thus, hydrophobic interactions between the 4-azasteroid (finasteride/dutasteride) and specific wild-type $5 \alpha$ reductase residues may be important for the slow, time-dependent inhibition displayed by these inhibitors. Pharmacogenetic analysis of these $5 \alpha$-reductase variants with another 4-azasteroid, such as PNU157706 (di Salle et al. 1998) may be instrumental in confirming this observation.

In summary, our systematic analysis of both constitutional and somatic (prostate cancer) variants of steroid $5 \alpha$-reductase type II indicates that dutasteride is a more efficient steroid $5 \alpha$-reductase type II inhibitor than finasteride in vitro for most of the enzyme variants, and that dutasteride treatment is also expected to result in lower pharmacogenetic variation in vivo than finasteride treatment. However, the pharmacogenetic variation we uncovered for both finasteride and dutasteride is still very significant and this should be taken into account when designing protocols for treatment and/or chemoprevention of prostatic diseases with either one of these drugs. Our data also suggest that both finasteride and dutasteride are slow, timedependent inhibitors of steroid $5 \alpha$-reductase type II and allow us to map areas of the wild-type enzyme that are (at least partially) responsible for this time-dependent inhibition for either (or both) enzyme inhibitor(s). Pharmacogenetic analyses such as the one presented here may one day help in achieving individualized prostate cancer treatment (and perhaps even prevention).

\section{Acknowledgements}

This work was supported in part by grants from GlaxoSmithKline, NCIR0168581 and NCIPOI108964 (project 1) to J K V R. We thank Roger Rittmaster (GlaxoSmithKline) for helpful comments on this manuscript.

\section{References}

Bramson HN, Hermann D, Batchelor KW, Lee FW, James MK \& Frye SV 1997 Unique preclinical characteristics of GG745, a potent dual inhibitor of 5AR. Fournal of Pharmacology and Experimental Therapeutics 282 1496-1502.

Brown CT \& Nuttall MC 2003 Dutasteride: a new 5-alpha reductase inhibitor for men with lower urinary tract symptoms secondary to benign prostatic hyperplasia. International Journal of Clinical Practice 57 705-709.

Cheng E, Lee C \& Grayhack J 1993 Endocrinology of the prostate. In Prostate Diseases, pp 57-71. Eds H Lepor \& RK Lawson. Philadelphia, PA: WB Saunders.

Clark RV, Hermann DJ, Cunningham GR, Wilson TH, Morrill BB \& Hobbs S 2004 Marked suppression of dihydrotestosterone in men with benign prostatic hyperplasia by dutasteride, a dual 5 alpha-reductase inhibitor. Fournal of Clinical Endocrinology and Metabolism 89 2179-2184.

Faller B, Farley D \& Nick H 1993 Finasteride: a slow-binding 5 alpha-reductase inhibitor. Biochemistry 32 5705-5710.

Frye SV, Bramson HN, Herman DJ, Lee FW, Sinhababu AK \& Tian G 1998 Discovery and development of GG745, a potent inhibitor of both isozymes of 5 alpha-reductase. Pharmaceutical Biotechnology 11 393-422.

Jaffe JM, Malkowicz SB, Walker SH, MacBride S, Peschel R, Tomaszewski J, van Arsdalen K, Wein AJ \& Rebbeck TR 2000 Association of SRD5A2 genotype and pathological characteristics of prostate tumors. Cancer Research 60 1626-1630.

Kyte J \& Doolittle RF 1982 A simple method for displaying the hydropathic character of a protein. Fournal of Molecular Biology 157 105-132.

Lowe FC, McConnell JD, Hudson PB, Romas NA, Boake R, Lieber M, Elhilali M, Geller J, Imperto-McGinely J, Andriole GL, Bruskewitz RC, Walsh PC, Bartsch G, Nacey JN, Shah S, Pappas F, Ko A, Gook T, Stoner E, Waldstreicher J. The Finasteride Study Group (2003) Long-term 6-year experience with finasteride in patients with benign prostatic hyperplasia. Urology 61 791-796.

McConnell JD, Bruskewitz R, Walsh P, Andriole G, Lieber M, Holtgrewe HL, Albertsen P, Roehrborn CG, Nickel JC, Wang DZ, Taylor AM \& Waldstreicher J 1998 The effect of finasteride on the risk of acute urinary retention and the need for surgical treatment among men with benign prostatic hyperplasia. Finasteride Long-Term Efficacy and Safety Study Group. New England Fournal of Medicine 338 557-563.

Makridakis NM, Ross RK, Pike MC, Crocitto LE, Kolonel LN, Pearce CL, Henderson BE \& Reichardt JKV 1999 A missense substitution in the SRD5A2 gene is associated with prostate cancer in African-American and Hispanic men in Los Angeles. Lancet 354 975-978.

Makridakis NM, di Salle E \& Reichardt JKV 2000 Biochemical and pharmacogenetic dissection of steroid $5 \alpha$-reductase type II. Pharmacogenetics 10 407-413.

Makridakis NM, Akalu A \& Reichardt JKV 2004 Identification and characterization of somatic steroid $5 \alpha$-reductase (SRD5A2) mutations in human prostate cancer tissue. Oncogene $\mathbf{2 3}$ $7399-7405$.

Moss ML, Kuzmic P, Stuart JD, Tian G, Peranteau AG, Frye SV, Kadwell SH, Kost TA, Overton LK \& Patel IR 1996 Inhibition of human steroid 5 alpha reductases types I and II by 6-aza-steroids: structural determinants of one-step vs two-step mechanism. Biochemistry 35 3457-3464. 
Ross RK, Pike MC, Coetzee GA, Reichardt JKV, Yu MC, Feigelson H, Stanczyk FZ, Kolonel LN \& Henderson BE 1998 Androgen metabolism and prostate cancer: establishing a model of genetic susceptibility. Cancer Research 58 4497-4504.

Russell DW \& Wilson JD 1994 Steroid 5 alpha-reductase: two genes/two enzymes. Annual Review of Biochemistry 63 25-61.

di Salle E, Giudici D, Radice A, Zaccheo T, Ornati G, Nesi M, Panzeri A, Delos S \& Martin PM 1998 PNU 157706, a novel dual type I and II 5 alpha-reductase inhibitor. Fournal of Steroid Biochemistry and Molecular Biology 64 179-186.

Span PN, Voller MC, Smals AG, Sweep FG, Schalken JA, Feneley MR \& Kirby RS 1999 Selectivity of finasteride as an in vivo inhibitor of 5 alpha-reductase isozyme enzymatic activity in the human prostate. Fournal of Urology $161332-337$.

Stoner E 1996 5 $\alpha$-Reductase inhibitors/finasteride. Prostate 6 82-87.

Thompson IM, Goodman PJ, Tangen CM, Lucia MS, Miller GJ, Ford LG, Lieber MM, Cespedes RD, Atkins JN, Lippman SM, Carlin SM, Ryan A, Szczepanek CM, Crowley JJ \& Coltman CA
Jr 2003 The influence of finasteride on the development of prostate cancer. New England Fournal of Medicine 349 215-224.

Tian G, Stuart JD, Moss ML, Domanico PL, Bramson HN, Patel IR, Kadwell SH, Overton LK, Kost TA, Mook RA Jr, Frye SV, Batchelor KW \& Wiseman JS 199417 Beta-(N-tertbutylcarbamoyl)-4-aza-5 alpha-androstan-1-en-3-one is an active site-directed slow time-dependent inhibitor of human steroid 5 alpha-reductase 1. Biochemistry 33 2291-2296.

Tian G, Mook RA Jr, Moss ML \& Frye SV 1995 Mechanism of time-dependent inhibition of 5 alpha-reductases by delta 1-4-azasteroids: toward perfection of rates of time-dependent inhibition by using ligand-binding energies. Biochemistry $\mathbf{3 4}$ 13453-13459.

Received 22 July 2004

Accepted 1 February 2005

Made available online as an Accepted Preprint 9 February 2005 